\title{
Towards a Well-functional Computerized Health Management Information System: A case of Mbagathi County Hospital, Kenya
}

\author{
Caroline Kawila Kyalo \\ Department of Health Systems \\ Management, School of Medicine and Health \\ Sciences \\ Kenya Methodist University
}

\author{
George W. Odhiambo-Otieno \\ Department of Health Systems \\ Management, School of Medicine and Health \\ Sciences \\ Kenya Methodist University
}

\begin{abstract}
Health Management Information Systems (HMISs) initiatives in Kenya have traditionally been donor-driven with minimal, if any, organizational input in their design. This has consequently led to predictable failures due to lack of sustainability of these initiatives upon donor pullout. The objectives of the study were to investigate the design, implementation and operation of Medboss computerized system at Mbagathi County Hospital in Kenya. Medboss is a locally developed computerized HMIS software, specifically designed for government hospitals in Kenya. However, private hospitals have also adapted it. A descriptive case study research design was conducted in the month of August 2015. The target population was sixty staff members who use Medboss, out of the sixty, thirty two participated in the study. Semi-structured questionnaires and key interview guides were used to collect data. Ten key informants, involved in the design and implementation of the system were interviewed. Questionnaires were used to collect data from twenty two health workers on their knowledge of the factors affecting the operation of the system. Collected data was analyzed using descriptive statistics and multiple regression analysis. Results: Design, implementation and operationalization revealed $73.3 \%$ effect on functionality of HMIS. Design was found to significantly influence functionality of HMIS, with a coefficient of 0.815 . The coefficient of implementation of HMIS was 0.703, which was equally significant. Operationalization had the least influence on functionality of HMIS with a coefficient of 0.412. Recommendation: Establish a fully functional computerized system. Develop an HMIS policy for the Hospital that documents its vision, mission and objectives therefore implementation will be based on the policy. Fully implement the remaining modules of the system, such as, pharmacy, nursing, human resource, logistics management, and special clinics to enable well-functioning in the operation of the system. Invest more in IT infrastructure in order to enjoy the full benefits of the current system.
\end{abstract}

\section{Keywords}

HMIS, Medboss, Mbagathi, Design, Implementation, Operation, ICT

\section{INTRODUCTION}

Health systems consist of all the people and actions whose primary intent is to promote, restore or maintain health. A health system is made up of a framework of six building blocks. The building blocks are: service delivery; health workforce; information system; medical products, vaccines and technologies; financing; and leadership and governance/ stewardship [1]. One way of strengthening a health system is to ensure the information pillar supports all other pillars by providing right information to the right persons, at the right time for purposes of timely decision-making. There is a widespread recognition that the world is changing and healthcare industry is one area facing unprecedented challenges [2].

Digital revolution is one development that has fundamentally changed the healthcare industry. In response to this rapidly changing environment, healthcare institutions in Kenya have to take necessary actions to pursue opportunities presented by these challenges, as well as responding positively to the challenges. However, [3] affirms that technology alone isn't enough. It is a vehicle for achieving value through automation. Investing in Information and Communication Technology (ICT) projects such as an HMIS have helped organizations' to achieve strategic objectives better. These efforts, further contribute to increased efficiency in the delivery of healthcare. Therefore, having a well-functioning HMIS is crucial as it could provide hospital service providers with the right information and feedback necessary to create value for the institutions [4].

\section{A WELL FUNCTIONIONAL HMIS}

A well-functioning Health Management Information System (HMIS) is one that ensures storage, production, analysis, dissemination and use of reliable, timely information in health determinants, health system performance and also in health status [1]. A well-functioning HMIS automates management reporting to support administrative and patient care applications and to reduce time and effort spent on the part of service delivery in the hospital [5] [6]. Furthermore, wellfunctioning HMIS's comprise of hardware, software and people in order to ease the management and flow of information among health care stakeholders. They should also focus on issues such as, patient-care, cost-efficiency, improved service quality, adaptability to the organizational context, and an integrated use of the information at both general hospital administration and clinical service delivery levels [7]. The current climate in the healthcare industry dictates a paradigm shift in health information management by removing manual records and transferring them into electronic information, standardization of health system and processes, real time monitoring of hospital performance, development of good communication and transformation of data through complex structure of the health system to help provide the right people with the right information at the right time.

In recent years, documents in paper form have been increasingly replaced by electronic documents in most types of organizations [8]. Hence the need for a plan on how the 
records will be managed considering not all records are stored electronically. The use of electronic documents provides an advantage over physical documents, in particular due to easier and efficiency in retrieval of information [8]. Management information system have been developed to help address stakeholder needs with respect to quality, the environment, safety and social accountability among others [9]. However, according to [5] the greatest challenges in hospitals in Kenya have been of equipping the IT department which spearheads the operation of the HMIS, development of IT strategy and enterprise architecture. A proper ICT architecture operationalizes an HMIS effectively and efficiently. Some of the challenges faced by Mbagathi County Hospital as they adopt ICT in their daily business transactions include; security issues, infrastructure, technical know-how, frequent power outages, lack of a proper forum to educate health workers on how to use ICT facilities, etc. As much as this is the case, this study argues that healthcare providers and governments have no choice but to meet healthcare demands for future citizens and the application of ICT is therefore fundamental and inevitable.

\section{HMIS IN MBAGATHI COUNTY HOSPITAL}

\subsubsection{Design of HMIS}

The Ministry of Health $(\mathrm{MoH})$ in Kenya recognizes the need to improve use of ICT in healthcare organizations [10]. Under Strategic Objective Five of the Heath Information System (HIS) Strategic Plan 2009-2014, the HIS aimed to strengthen the use and application of ICT in data and information management. It is with this objective in mind that $\mathrm{MoH}$ embarked on standardizing HMIS systems in Kenya.

Findings showed that Mbagathi County Hospital operates with several sub-systems. $64 \%$ of the respondents confirmed they use both electronic and manual systems (IQ care and Medboss). Medboss was the main HMIS operating in the hospital. Designing is one of the most important phase in developing any information system. In literature the design of any information system is informed by different organizational requirements. However this study found the following four to be key:

- Understanding the objectives of the organization

- Knowing the user roles and responsibilities

- Identifying data that was being collected

- The business process in the organization (information flow).

Mbagathi county hospital in the year (2011) adapted Medboss, an HMIS which the hospital had identified. The need for the system was to help the hospital manage the patients well. The choice of the system was also dependent on the fair cost of acquiring it. The functional areas were considered equally important by the hospital. When reviewed it was scored $7 / 17$,but since Medboss was a customizable system and the problems identified (variables levels of functionality, issues of long term sustainability, variable reporting functionality, limited ability to exchange information between systems) could be worked on, Mbagathi bought it.

At the time of this study, IQ Care was also in use in Mbagathi County Hospital in the Comprehensive Care Clinic which was a donor driven programme. The researcher found out that Mbagathi County Hospital used information generated by Medboss to feed the IQ Care system and the DHIS2. DHIS2 generates reports for the National level. The purpose of this study was to improve the functionality of the HMIS in Mbagathi County Hospital in order to sufficiently enable the adequate execution of hospital functions for patient care, including patient administration, taking into account economic hospital management as well as legal (e.g. data protection or reimbursement aspects) and other requirements.

\subsubsection{Objectives of HMIS in Mbagathi County Hospital}

Mbagathi County Hospital, Health Management Team (HMT) outsourced a system that would help them comply with the requirements by MoH. HMT had representatives from both the clinical (clinical officers, pharmacist, lab technologist, radiologist, ophthalmology) and administrative sections (finance, medical superintendent, health information and records, human resource manager) of the hospital who reported the roles and responsibilities of their departments. The study found out that the objectives of the Medboss were I) to ensure patient's information is captured, stored safely and can easily be retrieved, ii) to help clinical staff in decision making during healthcare service delivery, iii) to ensure revenue is collected for every service offered and iv) to support the in-charge of the hospital in monitoring and control at a click of a button.

\subsubsection{User roles and Responsibilities}

Users of the system were as follows: Clinical support: Clinical Officer, Lab Technologist, Radiologist, Ophthalmology, and Administrative Support: Medical Superintendent, accountants, Health Records and Information Managers. Users not taken care of by Medboss pharmacists, nurses, TB clinic, Gynecologists, Human resource manager. Study findings showed that majority of the users at $21.9 \%$ were clinical officers with minority at $3.1 \%$ who were administrative staff. This implies the main business in a hospital is to treat and manage the patients. Hence the patient's care was critical in this setting. This observation had been reported by [11] that HMIS in Kenya were mainly concerned with the collection of health services (patient) data as opposed to administrative. However the study emphasizes that administrative data is equally important and despite the administrative users being the minority their needs must be taken into account otherwise this trend continues to affect planning and managing health facilities. $57 \%$ of the respondents implied that their needs were met with $20 \%$ respondent's needs not met and $23 \%$ needs were partially met.

User's roles and responsibilities included information gathering, storing, analyzing, monitoring \& control, reporting and sharing. Findings showed that user roles \& responsibilities involved decision making on both clinical and administration issues. However $50 \%$ of the respondents reported that they had developed their own way of working because the system most of the times never met their needs.

The systems theory defines an organization as a body of interrelated parts. Therefore if some part of the system is not working well it affects the functionality of the whole system. Despite patient data being quite well represented, so many gaps were identified by the respondents' for example key data fields missing leading to inadequate treatment information. This affects the functioning of HMIS in Mbagathi County Hospital.

\subsubsection{Data Collected}

Data collected included patients demographics, symptoms, diagnosis, cost of services and cost of drugs. Key data fields 
left out, pharmacy management data, human resource management data, nursing care, bed management. [11] Had reported that most HMISs were mainly concerned with the collection of health services (patient) data as opposed to administrative data which still is the case in 2015. Therefore this has continued to affect the planning and management of health facilities. Yet in a review by [12], they emphasized that data collected should also inform policy makers. This results agree with his findings because they indicate that medical errors, planning and management of health system in Kenya continue to be affected unless the trend changes.

\subsubsection{Business Process}

Organization information flows mirrors the business activities/process in organization. Information flow is the connector between one departments to another in supporting decision makers. Hence organizing the activities of an HMIS in an organization helps in building an effective organization [13]. Study findings showed that Information flow in the hospital was not smooth hence hindering the utilization of the system. The challenge observed during the study was the back and forth movement of patients from one section to finance to another section and back again to finance. This was quite draining for a patient who was already unwell and it also created unnecessary queues leading to inefficiency and ineffectiveness.

\subsection{Implementation of HMIS}

A study by [11] revealed that in 1983, the Government of Kenya (GoK), decentralized the Ministry of Health's $(\mathrm{MoH})$ decision-making process to the districts. This was in line with World Health Organization (WHO) resolution calling on all WHO member states to strengthen District Health Systems (DHS). The GoK recognized that without an effective and appropriate information system, the MoH's capacity to cope with its planning and management needs would be severely compromised. Following this decentralization, Health Information Systems (HISs) at the district level in Kenya have undergone fundamental changes that have resulted in the introduction of different types of information systems. A quick survey of Kenya's MoH revealed that it operates different versions of District Health Management Information Systems (DHMISs) at the DHS level. The different systems were increasingly being adopted in different parts of the healthcare system in Kenya to improve medical records and information management, health program management, facility management and the quality of patient care.

$\mathrm{MoH}$ in 2010 came up with a HIS policy as a result of studies and reports that proved that functioning of HIS in Kenya was weak due to lack of an institutional regulatory framework. It was envisioned that the policy shall guide the health sector in developing and implementing information system that will produce quality benchmarks towards achieving its vision.

Change is inevitable, and an organization that does not respond to its changing environment may atrophy and cease to exist [14]. Healthcare organization are implementing HMIS in response to change. Thus, implementing HMIS solutions in organizations may require many changes related to production strategy, business processes, and work practices [8] even in the future.

Implementing an HMIS which is not only hardware and software but also the people (who need to be trained and committed to embrace change), processes, and structures (policy) that create, produce, and manage the information necessary to accomplish organizational goals and objectives.
Implementing an HMIS, therefore, involves having a policy in place, competent staff and a maintaining strategy. However in Mbagathi county hospital this was not the scenario.

The study findings emphasize on the need to improve on the areas shown in the Figure1 below, so as to ensure computerized HMIS implementation in Mbagathi County Hospital is well functioning as well as adds value to the hospital.

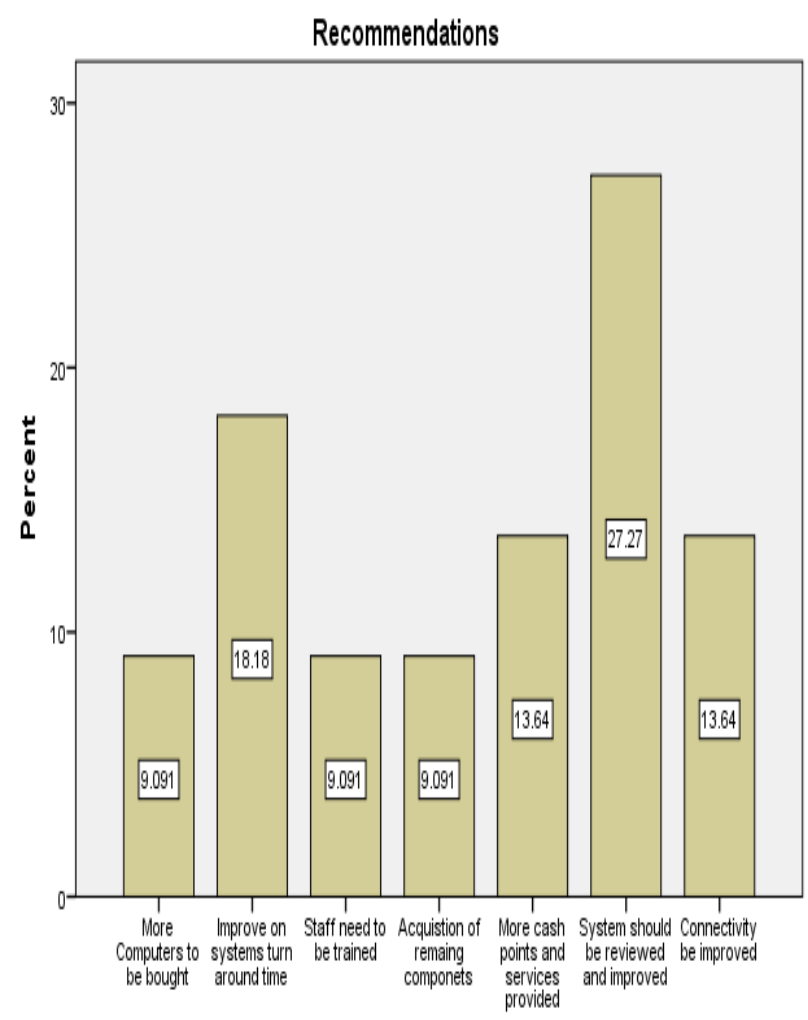

Recommendations

Figure 1: Recommendation made to ensure value is gained for computerized HMIS implementation

\subsubsection{Policy Document}

Mbagathi County Hospital did not have any HMIS policy in place. A good policy document would help to determine whether the system was meeting its intended purpose. It could also be used as a reference document when it comes to upgrading or reviewing the current system. Policy guides in setting priorities regarding a certain matter. The study found out that Mbagathi county hospital had no institutional policy documents in place in relation to HMIS, yet according to [15] lack of policy documents led to failures in implementation of HMIS. There was no direction in regards to the implementation process, budgets, and neither were there set standards which could be used to check on compliance. The hospital had no plan in place on how to sustain the system in terms of where to source for resources to maintain it or even upgrade it. This had already had a negative impact on the functioning of the system because the hospital could not implement the remaining modules due to lack of planning in regards to financial resources.

\subsubsection{Ease of use of the system}

Study findings showed that Majority of the staff members could use the system without training as long as they were computer literate. It was evident that the system was also user 
friendly. However [16], argued that lack of education and training could be as a major impediment in the successful adoption of IS in Healthcare sector. Hence to increase the HIS adoption and maintain a professional relevance, it would be important that healthcare workers undergo a process of continuous training. Researchers usually refer to this as, workrelated learning [17], which is learning related to work, that takes place in and at work, as well as outside the workplace. However, many healthcare organizations, when implementing HIS projects, do not consider the direct and indirect cost of training and do not train their employees on HIS [18], which was the same case in Mbagathi County Hospital.

\subsubsection{Sustainability of the system}

Mbagathi County Hospital had no financial plan or a budget in place in the hospital to maintain and sustain the system. It was reported that the system was to be implemented in three phases but this had not been achieved by the time of the study. The hospital had only implemented the first phase (outpatient) and some of the departments in the first phase were actually not automated. [11] Emphasized that organizations should be cautious of their financial viability, because sustainability becomes important and is dependent on the planning in phase. Financial viability criterion measures, first, what the system will cost, and second what it will produce for benefits. This was found to be a critical factor that Mbagathi County Hospital needed to consider.

\subsection{Operation of HMIS}

Adoption of a well-functioning health management information system (HMIS) as tool, can be used to improve service delivery to patients in health care institutions by tracking certain dimensions of service quality. Quality can be checked by comparing perceptions of services delivered with the expected standards. One of the objectives of the HMIS was to record information on health events and check the quality of services at different stations in the hospital. Overall, a wellfunctioning HIS is an integrated effort to collect, process, report and use health information and knowledge to influence policy and decision-making, programme action, individual and public health outcomes, and research. At a policy level, decisions informed by evidence contribute to more efficient resource allocation and, at the delivery level, information about the quality and effectiveness of services can contribute to better outcomes [19].

\subsubsection{Document Management}

Findings showed that Mbagathi hospital was keen in ensuring sound records management practice because, they had trained staff, they were keen to ensure records were complete and they had a disposal record policy. However the disposal policy was not adhered to most of the time hence bringing in a lot of confusion. To effectively manage the movement of files and records they coded them but due to bulkiness it became quite a challenge to locate them. Sometimes a record was stored in both electronic record and a paper record. At times the records were synchronized and other times this was not done, hence bringing in a challenge of having incomplete records

\subsubsection{Retrieval of documents}

Findings indicated that waste of time was experienced when searching for paper records. Hence necessitated Mbagathi county hospital in 2010 to move to electronic record keeping despite the fact that several document were still kept in file cabinets. This still caused them challenges when retrieving from either from the system or the cabinet. The courses of this challenges are shown in the table below
Table 1. Challenges caused by way of storage

\begin{tabular}{|c|c|c|c|c|}
\hline $\begin{array}{c}\text { Storage } \\
\text { Design }\end{array}$ & $\begin{array}{c}\text { Strongly } \\
\text { Agreed }\end{array}$ & Agreed & $\begin{array}{c}\text { Somehow } \\
\text { agreed and } \\
\text { disagreed }\end{array}$ & Agreed \\
\hline Electronic & $\begin{array}{c}\text { Some key } \\
\text { data fields } \\
\text { are missing }\end{array}$ & $\begin{array}{c}\text { Unavailabilit } \\
\text { y when } \\
\text { system is } \\
\text { needed }\end{array}$ & $\begin{array}{c}\text { Hangs a lot } \\
\text { and very } \\
\text { slow }\end{array}$ & $\begin{array}{c}\text { Power } \\
\text { Challen } \\
\text { ges }\end{array}$ \\
\hline Manual & $\begin{array}{c}\text { Cabinets } \\
\text { are } \\
\text { overcrowd } \\
\text { ed with } \\
\text { paper }\end{array}$ & $\begin{array}{c}\text { Poor } \\
\text { labelling }\end{array}$ & Security & $\begin{array}{c}\text { Time } \\
\text { wasting }\end{array}$ \\
\hline
\end{tabular}

This has led to data not being sufficiently used to inform improvement in service delivery, policy development, strategic planning, or advocacy. Part of the reason for the breakdown in the process is that HMIS are fragmented and do not fully respond to information needs.

The study concluded that the key factors that were affecting operation of HMISs in Mbagathi County Hospital were more of infrastructure issues which included connectivity, power, incomplete system installations and storage overload. This results were consistent with those of [20]; [5] in determining the challenges of operationalization on of HMIS in hospitals in Kenya.

\subsubsection{Security of data stored}

Document security especially in the health sector is quite a sensitive issue. Risks of this information being exposed are quite high. Security and privacy policies are required to handle this problem. Therefore Mbagathi county hospital put measure in place. This had been done in two phases I) for the electronic records every user had an account to show what they do using the system. ii) For the paper records anyone who picked a document signed for it and the same was done when they return it

\subsection{Regression Output}

It was observed from the results in Table 2 of the model summary that the adjusted $\mathrm{R}$ square implies that the independent variables of the study; design, implementation and operationalization explained $73.3 \%$ of functionality of HMIS, meaning they are important variables.

Table 2. Regression Output

\begin{tabular}{|l|l|l|l|l|l|}
\hline & $\begin{array}{l}\text { Coeffi } \\
\text { cients }\end{array}$ & Std. Error & $\begin{array}{l}\text { Standardi } \\
\text { zed } \\
\text { Coefficie } \\
\text { nts } \\
\text { Beta }\end{array}$ & t & Sig. \\
\hline $\begin{array}{l}\text { (Cons } \\
\text { tant })\end{array}$ & 3.44 & .327 & .677 & 9.912 & .009 \\
\hline $\begin{array}{l}\text { Desig } \\
\text { n }\end{array}$ & .815 & .039 & .620 & 7.148 & .005 \\
\hline $\begin{array}{l}\text { Imple } \\
\text { ment } \\
\text { ation }\end{array}$ & .703 & .062 & .320 & & \\
\hline $\begin{array}{l}\text { Oper } \\
\text { ation }\end{array}$ & .412 & .087 & .214 & 16.520 & .003 \\
\hline
\end{tabular}

a. Dependent Variable: Functionality of HMIS 
Table 3. Model Summary

\begin{tabular}{|l|l|l|l|l|}
\hline Model & R & $\begin{array}{l}\text { Adjusted } \\
\text { R square }\end{array}$ & $\begin{array}{l}\text { Std. Error of } \\
\text { Estimate }\end{array}$ & $\begin{array}{l}\text { R } \\
\text { squar } \\
\text { e } \\
\text { chang } \\
\text { e }\end{array}$ \\
\hline 1 & $878^{\mathrm{a}}$ & .733 & .617 & .743 \\
\hline
\end{tabular}

a. Predictors: (Constant), design, implementation and operationalization

\section{CONCEPTUAL FRAMEWORK}

The conceptual framework offered the conceptual foundation and the elaborate network of association among the variables deemed relevant for the problem situation. The conceptual framework comprised of three important variables classified as below:

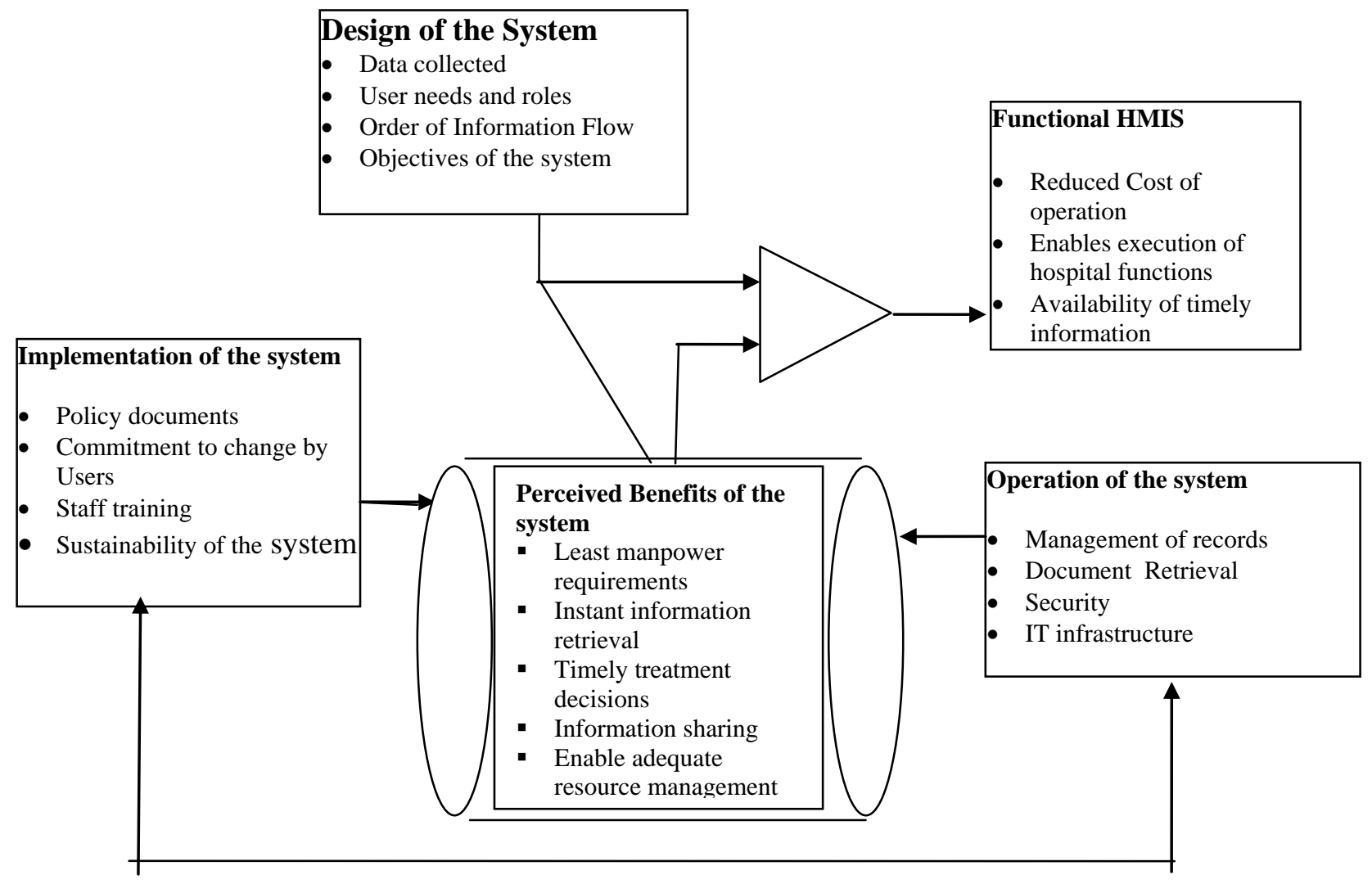

Fig 1: Conceptual Framework

\section{CONSTRAINTS}

As compared to developed countries HMIS implementation in Kenyan hospitals are still handicapped. They have significant shortage of resources. Apart from that they are have revealed numerous problems with the various electronic systems, including:

- Variable levels of functionality and data security

- Unpredictable vendor/technical support

- Issues with long-term sustainability

- Variable reporting functionality

- $\quad$ Limited feedback of data in systems for patient care

- $\quad$ Limited ability to exchange information between systems.

It was proposed by [12] that one approach to addressing these issues was to adopt a single system for all healthcare settings in Kenya. However, $\mathrm{MoH}$ also acknowledged that information needs differed across different settings and even within the public health sector. These were according to facility size, technical capacity, the presence or absence of specific activities such as clinical trials which may impact workflow and health information, goals and requirements of donor agencies, development partners, and other factors. Given that needs, capacity, and funding differ across institutions, and that a number of systems tailored to meet these different needs are already in use across Kenya, it was not feasible for $\mathrm{MoH}$ to enforce a single national HMIS

According to [20] study findings indicated that the HMIS in Kenya do not deliver quality data, because significant constraints existed in data quality assurance, supervisory support, data infrastructure in respect to information and communications technology application, human resources, financial resources, and integration. However, there has been significant efforts to have effective HMISs over the past 10 years, the development and implementation of these systems has not properly coordinated, resulting in multiple systems with varying objectives and functionality, without the ability to share patient and administrative information with other systems, programs, and the MoH. Therefore this created a lot of interest in the study. 


\section{KEY REQUIREMENTS FOR ENSURING HMIS IN MBAGATHI COUNTY HOSPITAL IS WELL- FUNCTIONAL}

- There is need for an effective and appropriate information system, hence inclusion of the missing data fields and modules is key

- It is important to involve all the users in designing the system so that the design can be matched the user needs

- Have a proper institutional HMIS policy

- Have a financial plan or a budget in place in the hospital to maintain and sustain the system

- Improve on the ICT infrastructure in the hospital

\section{CONCLUSION AND RECOMMENDATIONS}

The study concludes that Medboss as a HMIS was designed to collect both administrative and clinical data for purposes of effective and efficient decision making as well as planning for the hospital. However the hospital has not implemented all the modules such as bed management, nursing, human resource management and drug management. Findings also indicate that Mbagathi Couty hospital lacks policy documents that guide successful implementation of the system. As a result this has led to no set standards that can be used to measure compliance, budget to maintain and improve the system. nadeaqate ICT infrastructure, interms of power, connectivity, backups, storage leading to hanging or slow operation on the system and missing data fields are also identified as constrains of utilisation of the system.

The study recommendation are as follows: Mbagathi County Hospital should fully implement the remaining modules of the system and also review the system to take care of the rapidly changing environment, it should develop an institutional policy document e.g. an HMIS policy, budgets, terms of reference documents where they have engaged consultants or suppliers and needs to invest more in IT infrastructure in order to enjoy the full benefits of ICT.

\section{ACKNOWLEDGMENTS}

Special thanks to German Academic Exchange Service (DAAD) and the Federal Ministry of Education.

\section{REFERENCES}

[1] WHO, (2007). Strengthening Health Systems to Improve Health Outcomes. Geneva, Switzerland: WHO Document Production Service.

[2] Ranganathan, C. W.-M. (2004). Bringing professionals on board lessons on executing IT-enables organizational transformation

[3] Greenes, R. a. (1998). Audacious goals for health and biomedical informatics in the new millennium. Journal of American Medical Informatics Association, 395-400.

[4] Cox, K. D. (1999). ABC's of higher education - getting back to the basics: an activity-based costing approach to planning and financial decision making. Seattle, WA: Institutional Research 39th Annual Forum.

[5] Kimama, F. M. (2011). Challenges Facing the Implementation of Hospital Management Information Systems in Hospitals in Nairobi. Nairobi

[6] Tan, J. (2005). E-Health Care Information Systems: An Introduction for Students and Professionals. John Wiley \& Sons.

[7] Ovreitveit, J. (1992). Health Services. Blackwell Scientific Publication.

[8] Haug, A. (2012). The implementation of enterprise content management systems in SMEs. Journal of Enterprise Information Management

[9] Searcy, C., Morali, O., Karapetrovic, S., Wichuk, K., McCartney, D., McLeod, S., \& Fraser, D. (2012). Challenges in implementing a functional ISO 14001 environmental management system. International Journal of Quality \& Reliability Management, 29(7), 779-796. http://doi.org/10.1108/02656711211258526

[10] Sherburne. (2010). Standards and Guidelines for Electronic Medical Records Systems in Kenya.

[11] Odhiambo-Otieno, G. W. (2005). Evaluation of existing District Health Management Information Systems: A case study of the District Health Systems. International Journal of Medical Informatics, 733-744.

[12] MoH. (2011). Report on the Review of EMR Systems: Towards Standardization Kenya Ministries of Health.

[13] Petrauskas, V. (2015). The use of information flow analysis for building an effective organization. Information Technology and Control, 35(4).

[14] Hall, C. S., Fottrell, E., Wilkinson, S., \& Byass, P. (2014). Assessing the impact of mHealth interventions in low- and middle-income countries - what has been shown to work? Global Health Action, 7(0).

[15] Heeks, R. (2006). Health information systems: failure, success and improvisation. International Journal of Medical Informatics, 75(2), 125-137.

[16] Igira, F. T. (2012). The dynamics of healthcare work practices: Implications for health management information systems design and implementation. Management Research Review, 35(3/4), 245-259.

[17] Sambrook, S. (2001). Factors influencing learning in work: a comparison of two research projects. University of Twente, Enschede.

[18] Mantzana, V. T. (2008). Identifying healthcare actors involved in the adoption of information systems. European Journal of Information, 90-102.

[19] Naidu, S., \& Richards, N. (2011). HIS.

[20] Kihuba, E., Gathara, D., Mwinga, S., Mulaku, M., Kosgei, R., Mogoa, W., English, M. (2014). Assessing the ability of health information systems in hospitals to support evidence-informed decisions in Kenya. Global Health Action, 7(0). 